\title{
Social influences on the development of ringtailed lemur feeding ecology
}

\author{
M. Teague O’Mara ${ }^{\mathrm{a}, \mathrm{b}, \mathrm{c}, *}$, Cathriona M. Hickey ${ }^{\mathrm{d}, \mathrm{e}}$ \\ a Smithsonian Tropical Research Institute, Balboa, Ancón, Panamá, República de Panamá \\ ${ }^{\mathrm{b}}$ School of Human Evolution \&' Social Change, Arizona State University, Tempe, U.S.A. \\ ${ }^{\mathrm{c}}$ Max Planck Institute for Ornithology, Department of Migration and Immuno-Ecology, Radolfzell, Germany \\ ${ }^{\mathrm{d}}$ CIRCLE, Environment Department, University of York, Heslington, York, U.K. \\ ${ }^{\mathrm{e}}$ Flamingo Land Ltd, Kirby Misperton, Malton, North Yorkshire, U.K.
}

\section{A R T I C L E I N F O}

Keywords:

co-feeding

Lemur catta

ontogeny

ringtailed lemur

social learning

stimulus enhancement

Social learning is common in animals and is used across age classes to learn about novel foods and to reduce potential costs associated with individual trial and error learning (Galef \& Giraldeau 2001; Mery \& Kawecki 2004; Hoppitt \& Laland 2008; van Schaik \& Burkart 2011; Thornton \& Clutton Brock 2011). Social learning is 'learning that is influenced by the observation of, or interaction with, a conspecific or its products' (Hoppitt \& Laland 2008, page 105; also see Heyes 1994). It enables the accumulation of complex behaviours and may be at the root of intelligence across bird and mammal species (Emery \& Clayton 2004; van Schaik \& Burkart 2011). Social learning has a pivotal role in the develop ment of skills and social behaviours (Thornton \& Raihani 2008; Thornton \& Clutton Brock 2011), and may be particularly important in species with extended juvenile periods (Joffe 1997; Ross \& Jones 1999). Young animals from species that live in permanent social groups may have multiple social partners from which to learn, and may adjust their behaviour to maximize learning opportunities

\footnotetext{
* Correspondence: M. T. O’Mara, Smithsonian Tropical Research Institute, Apartado 0840-0153, Panamá, República de Panamá.

E-mail address: teague.omara@gmail.com (M. T. O’Mara).
}

from a more diverse set of social partners. Monkeys and apes use a wide diversity of behaviours, tactics and strategies to learn from others (Whiten 2000; Laland 2004; Humle \& Snowdon 2008), but the commonality and developmental use of these behaviours and strategies across taxa is unclear. Because of its importance in social groups (Richerson \& Boyd 2005), understanding the diversity and evolution of social learning affects our understanding of how social interactions and the use of social information shape the stability of diverse social systems.

Many vertebrate species are adept social learners (Whiten 2000), and social learning early in life may be a particularly important behavioural strategy in species with complex foraging regimes or generalist diets (e.g. Page \& Ryan 2005; Thornton \& Clutton Brock 2011). The use of social learning has been repeat edly documented in both the vertical and horizontal transmission of feeding, social and antipredator behaviours, with many of these behaviours particularly well documented in adult monkeys and apes (Whiten 2000; Dindo et al. 2009; Kawai 1965; Kendal et al. 2009, 2010; van de Waal et al. 2010; van de Waal \& Bshary 2011). Social transmission of behaviour accounts for much of the inter population variation attributed to culture or tradition, especially in primates, cetaceans and corvids (e.g. Whiten et al. 1999; Laland \& 
Janik 2006; Perry 2011; Whiten 2011; Luncz et al. 2012; van Schaik 2012). While social learning has been well tested in many monkey and ape taxa in captivity (Whiten 2000), few studies have exam ined social learning in the strepsirrhine primates, particularly in wild populations. Results from the few published studies on lemur species are often contradictory or equivocal, highlighting the need for further exploration in these species (Feldman \& Klopfer 1972; Anderson et al. 1992; Hosey et al. 1997; Gosset \& Roeder 2001; Krakauer 2005; Kendal et al. 2010; Dean et al. 2011; Stoinski et al. 2011). There has been even less emphasis on the way that infant and juvenile primates use social information and social learning within an ecological context, and how social information is used throughout development to guide feeding and foraging behaviour.

By necessity, feeding ecology is learned early in life (Thornton $\&$ Clutton Brock 2011), and early social experiences can set feeding behaviours and preferences well into adulthood (Slagsvold \& Wiebe 2007), as well as predict lifetime fitness (Altmann 1991). Execution of partner focused co feeding by juvenile vervet monkeys, Chlorocebus aethiops, is positively correlated with their survivorship (Hauser 1993), and protein and energy balance as a juvenile predicts female lifetime reproductive success in baboons, Papio cynocephalus (Altmann 1991), making the social influence on the development of diet particularly important (Altmann 1980). While these studies do not directly demonstrate social learning, they do point to the importance of infant and juvenile social environment on the development of diet, either through behav ioural participation of co feeding or through maternal effects that may facilitate higher quality diets. It is unknown whether these same behaviours and social rules also shape the developmental trajectory of all group living mammals, or whether there are both phylogenetic and ecological limitations on the distribution of social learning by young individuals.

The use of social learning has variable returns based on the learning behaviour used and the stability of both the social and physical environment (Hoppitt \& Laland 2008). For example, humans are more likely to incorporate the behaviour of their groupmates into their decision making process when social groups are stable than when social groups fluctuate (Toelch et al. 2009; Rendell et al. 2010). Some work suggests that the use of social learning may be adaptive only in environments with predictable resources (Hoppitt \& Laland 2008) and when the previous quality of someone's knowledge can be evaluated based on the relative age of the information and the stability of the environment (Rendell et al. 2010). Relatively few studies of social learning in wild pop ulations have been able to test these claims within an ecological context. However, these studies have shown that social learning can be plastic in the context of group and species feeding ecology (Slagsvold \& Wiebe 2007) and that social group members shape the development of feeding through a variety of behaviours (Thornton \& McAuliffe 2006; Thornton \& Clutton Brock 2011). Studies of wild primates have shown that social learning is biased along maternal lines or within social cliques (Kendal et al. 2010; van de Waal et al. 2010, 2012). These wild studies, however, have yet to identify the use of complex social learning behaviours observed in laboratory settings, which largely ignore basic social learning strategies such as social facilitation or local enhancement that may be responsible for the majority of learning opportunities (Galef \& Giraldeau 2001; Mersmann et al. 2011). There is then little understanding of how ecological stability affects the use of social learning in wild animal populations and how infants and juveniles incorporate both social and personal experience throughout their development.

Lemurs present an ideal system to understand the develop mental use of social learning as well as how environmental stability affects the use of social learning behaviours. Ringtailed lemurs, Lemur catta, are generalist frugivore-folivores that live in large multimale, multifemale social groups (Jolly 1966b). Diffusion analysis has shown that adult lemurs learn behaviours socially (Hosey et al. 1997; Kendal et al. 2010), but it has yet to be demonstrated how infant and juvenile lemurs learn from social behaviour, the frequency at which these social learning behaviours are used, how this varies by season, and the effect of social learning on overall fitness (Hauser 1993).

Here, our aim was to understand how social learning behaviours and potential social information are used in the development of feeding by young wild ringtailed lemurs in southwestern Madagascar. Using observational data, we identified behaviours of infant and juvenile ringtailed lemurs that were consistent with social learning (Rapaport \& Brown 2008). We then tested whether behaviours that were consistent with social facilitation strategies were likely to be responsible for social learning and whether focused social learning behaviours, such as co feeding, were also common and important in the development of ringtailed lemur feeding. We predicted that infants and juveniles would actively seek out individuals that were feeding, and that like monkeys, co feeding would comprise a large proportion of infant and juvenile feeding time. Young animals will feed and forage in closer prox imity to other group members and approach individuals that are feeding more often than they do individuals that are engaged in other behaviours. A more generalized social facilitation may also be common in which the behavioural synchrony with an individual's nearest neighbour is higher during foraging and feeding than during other social behaviours such as travel and grooming. Addi tionally, if exploration and trial and error learning contribute significantly to the way that young individuals learn about food, then infants and juveniles should show higher dietary diversity than adults.

\section{METHODS}

\section{Study Site}

Data were collected during May 2009-March 2010 at the Beza Mahafaly Special Reserve (Beza) in southwestern Madagascar $\left(23^{\circ} 39^{\prime} 25^{\prime \prime} \mathrm{S}, 44^{\circ} 37^{\prime} 43^{\prime \prime} \mathrm{E}\right)$. Beza's climate is highly seasonal, with a cold dry (May-September) and a hot wet (October-April) season, where $80 \%$ of the annual average of $615 \mathrm{~mm}$ of rain falls each year (Lawler et al. 2009). This study period was unusually hot and dry with average high temperatures of $35.7^{\circ} \mathrm{C}$ (dry season) and $45.8^{\circ} \mathrm{C}$ (wet season) and half the typical rainfall (this study: $265 \mathrm{~mm}$; Beza average for June-March: $500 \mathrm{~mm}$; O’Mara 2012; Sussman \& Ratsirarson 2006)

\section{Study Population}

Ringtailed lemurs live in multifemale, multimale social groups of 9-22 individuals. Contrary to the typical mammalian pattern, females dominate males in all contexts (Pereira \& Kappeler 1997) and dominant females can control access to small food patches and limit feeds in close proximity. Ringtailed lemurs breed annually, with all infants in a social group typically born within a period of 2-3 weeks (Sauther 1991; Jolly 1966a). They are eclectic frugivorefolivores that feed from over 137 plant and arthropod species (O'Mara 2012), most of which do not require extensive processing, although some fruits such as Tamarindus indica may require a minimum of strength or postcanine occlusal surface area to open and are not processed at adult levels until late in juvenility (O'Mara 2012).

Over 2300 observation hours were completed by five observers on a mixed longitudinal sample (infants through adults) of 78 individuals from seven study groups (see Table 1 for sample size 
Table 1

Number of individuals, total observation hours/age sex category, mean number of focal animal samples (FAS)/day and mean \pm SE number of hours/day that each individual was observed across the study period

\begin{tabular}{|c|c|c|c|c|c|}
\hline Age category & Sex & Number of individuals* & Total hours & Mean FAS/day & Mean \pm SE hours/day \\
\hline \multirow[t]{2}{*}{ Infant 1 (0 12 weeks) } & $\mathrm{F}$ & 14 & 93.4 & 5.0 & $1.015 \pm 0.064$ \\
\hline & $\mathrm{M}$ & 12 & 99 & 5.4 & $1.138 \pm 0.063$ \\
\hline \multirow[t]{2}{*}{ Infant 2 (13 24 weeks) } & $\mathrm{F}$ & 8 & 102.4 & 5.6 & $1.101 \pm 0.063$ \\
\hline & M & 10 & 112.2 & 5.8 & $1.122 \pm 0.068$ \\
\hline \multirow[t]{2}{*}{ Juvenile 1 ( 2552 weeks) } & $\mathrm{F}$ & 46 & 152.2 & 7.7 & $1.522 \pm 0.079$ \\
\hline & M & 13 & 46.2 & 7.3 & $1.444 \pm 0.135$ \\
\hline \multirow{2}{*}{ Juvenile 2 ( 12 years $)$} & $\mathrm{F}$ & 36 & 186.4 & 6.4 & $1.294 \pm 0.066$ \\
\hline & M & 16 & 136.8 & 6.6 & $1.303 \pm 0.073$ \\
\hline \multirow[t]{2}{*}{ Subadult ( 23 years) } & $\mathrm{F}$ & 3 & 82.4 & 5.1 & $1.043 \pm 0.067$ \\
\hline & M & 68 & 272.4 & 5.7 & $1.159 \pm 0.045$ \\
\hline \multirow[t]{2}{*}{ Adult ( $3+$ years) } & $\mathrm{F}$ & 2326 & 693 & 4.1 & $0.822 \pm 0.016$ \\
\hline & M & 1117 & 337 & 4.0 & $0.799 \pm 0.022$ \\
\hline
\end{tabular}

* Number of individuals includes animals that passed from one age category to the next.

and age category definitions). This included four birth cohorts (born from 2006 to 2009); thus, the same individuals within a cohort were observed as they grew from Infant 1 to Juvenile 1 , or from Juvenile 1 to Juvenile 2, or from Juvenile 2 to Subadult, or Subadult to Adult. This included 18 mother-offspring pairs: 12 mothers with infants, four mothers with offspring ages of Juvenile 1 or Juvenile 2, and two mothers and their older juvenile or subadult offspring. Some mothers had surviving offspring from more than one breeding year for at least part of the study. All infants and juveniles had mothers in the group throughout the duration of study. Infants begin moving independently and foraging from their mothers by 6 weeks of age, are responsible for their own travel by 14 weeks, and are fully weaned by 25 weeks (Gould 1990; O'Mara 2012). Birth dates are known for all individ uals born in each study group since 2006, but are not known for females older than 4 years or for adult males that transfer between groups. Adults were individually recognized by a combination of natural markings and a unique collar/tag combination placed on the animals by the Beza Mahafaly Lemur Biology Project. Young animals and adults without collars were marked with a small amount of Nyanzol D (Greenville Colorants, Jersey City, NJ, U.S.A.). Interobserver reliability was periodically assessed to maintain a minimum of $85 \%$ agreement using Cohen's Kappa statistic included in the JWatcher package (Coelho \& Bramblett 1981). All methods conformed to the ASAB/ABS Guidelines for the Use of Animals in Research and were approved by the Institutional Animal Care and Use Committee of Arizona State University (08 983R) and by Madagascar National Parks (81/09, 257/09).

\section{Behavioural Sampling}

Continuous and instantaneous sampling methods were used simultaneously to sample feeding and its social context. All feeding and foraging behaviours were continuously recorded in JWatcher (www.jwatcher.ucla.edu) during $12 \mathrm{~min}$ focal animal observation sessions, FAS (Altmann 1974). Feeding behaviours included feed (ingestion of food), food explore (placing item in mouth but not eating it), forage (active searching for and processing of food items), sniff food, sniff mouth, lick food, crack food and co feed (defined below). Additional social learning behaviours included beg, steal, scrounge and transfer food (Rapaport \& Brown 2008). These behaviours, however, were either not used by ringtailed lemurs or were observed only once and were excluded from analysis.

To measure maintenance of proximity, we continuously recor ded approaches and leaves initiated by or directed at the focal individual and divided them into approaches towards partners that were feeding and foraging and approaches towards partners that were engaged in other behaviours. Plant foods were identified to species with the help of local experts (Mr Elahavelo and Mr Herman Mananjo), by Mr Rokiman Letsara (Tsimbazaza Botanical Gardens, Antananarivo) and through digital voucher images from the Mis souri Botanical Gardens TROPICOS database (www.tropicos.org).

\section{Co feeding and neighbour synchrony}

We used two measures of feeding behaviour that could facilitate social learning. First, co feeding is a directed feeding association that approximates seeking out a partner to feed with or learn from. Co feeding is the simultaneous feeding with another individual within $1 \mathrm{~m}$ following approach by one of the individuals (Hauser 1993; Ueno 2005), and it has been commonly cited in primate studies as a particularly valuable social learning behaviour. Second, we included a more generalized measure of feeding synchrony to test for basic social learning consistent with local enhancement and stimulus enhancement strategies (Mersmann et al. 2011). To measure general behavioural synchrony, we recorded both the focal and its nearest neighbour's activity (nurse, feed, forage, rest, move, stand, engaged in social behaviours, other) instantaneously at $3 \mathrm{~min}$ intervals during the FAS. During these instantaneous samples, we also recorded the categorical distance to the nearest neighbour (touching, within arm's reach, within $1 \mathrm{~m}$, within $3 \mathrm{~m}$ and greater than $3 \mathrm{~m}$ away). We then identified behavioural synchrony when both the focal and its nearest neighbour were engaged in the same activity.

\section{Dietary diversity, evenness and overlap}

We constructed indices to measure dietary diversity and dietary overlap of focal animals in 2 week blocks. Dietary diversity was calculated using the inverse Simpson's diversity index, $D$, where $D \quad 1 /\left(\sum p_{i}^{2}\right)$ and $p_{i}^{2}$ is the squared proportion of total time feeding in these 2 week blocks on each item (species + part) (Begon et al. 1996; Irwin 2008). D originates from a value of 1 (diet of 1 item), with higher values reflecting a more diverse diet. We calculated an index of dietary overlap $(R)$ for all pairs of focal individuals within each group during these 2 week blocks. $R$ was calculated as $R \quad\left(\sum\left(p_{i j} \times p_{i k}\right)\right) / \sqrt{ }\left(\sum p_{i j}^{2} \times \sum p_{i k}^{2}\right)$, where $p_{i j}$ and $p_{i k}$ are the proportions of item $i$ in the diet of individuals $j$ and $k$ (Pianka 1973).

\section{Analysis}

Both continuously and instantaneously recorded data are summarized as proportions of total FAS per individual per day. This generates a mixed longitudinal data set of individual days with the intent of preserving any individual level variability in behaviour (Machlis et al. 1985; Dagosto 1994). Dietary diversity and overlap 
indices were calculated per individual in 2 week blocks. General ized linear mixed models (GLMMs) were then fitted to the mixed longitudinal data in the lme4 package in $\mathrm{R} 2.13$ (R Development Core Team 2011). Untransformed proportional data were modelled using logistic mixed models with a binomial distribution and logit link identity (Jaeger 2008; Warton \& Hui 2011). To control for the repeated sampling of the same indi vidual within age classes, we included individual identity and a time factor (season) as random effects (Carter et al. 2012; Hilborn et al. 2012). The goal then of these random factors was not to assess interindividual differences in behaviour, but to control for them as well as allowing for time controlled comparisons among age categories across the year. We evaluated the significance of the fixed factors (e.g. age, sex) by comparing two nested models differing in a single factor (Pinheiro \& Bates 2009; Huchard et al. 2012). We then used a likelihood ratio test of these two nested models $\left(\chi^{2}\right)$ to evaluate the significance of individual factors (Lewis et al. 2011). When factors did not contribute significantly to the fit of the model, they were removed from the analysis. For models with significant main effects, subsequent Tukey's post hoc tests identified differences between factor level pairwise comparisons, typically age-sex levels. All significance was evaluated at $\alpha \quad 0.05$.

\section{RESULTS}

\section{Social Learning in the Development of Feeding}

Infants fed and foraged on solid foods with closer nearest neighbours than did other age categories (Table 2). Infants were in contact, within reach and within $1 \mathrm{~m}$ of their nearest neighbour more than were all other age categories, placing them in closer proximity for social learning opportunities (touch: $\chi_{11}^{2} \quad 78.726$, $P<0.001$; reach: $\chi_{11}^{2}$ 59.555, $P<0.001 ; 1 \mathrm{~m}: \chi_{11}^{2} \quad 65.564$, $P<0.001$; Table 2 ). These infant proximity patterns during feeding and foraging did not simply reflect overall proximity patterns for infant ringtailed lemurs (Kolmogorov-Smirnov tests: Infant 1 : $D \quad 0.285, P<0.001$; Infant $2: D \quad 0.298, P<0.001)$. Infants were farther from their nearest neighbour during feeding than during other activities, including play, rest and travel. As infants are weaned into the Juvenile 1 age stage, they transition to adult like spacing patterns while feeding and foraging, with typical distances of 1 and $3 \mathrm{~m}$ from their nearest neighbours (Table 2). Infants and Juvenile 1 individuals were less likely than older groupmates to approach another individual that was feeding and foraging $\left(\chi_{5}^{2} \quad 20.501, P \quad 0.001\right.$; Fig. 1$)$.

The total proportion of feeding time that ringtailed lemurs engaged in co feeding was low (less than $10 \%$ of total feeding time for each age class; Fig. 2). Co feeding on the same part of the same plant species accounted for over $95 \%$ of the time spent co feeding. In the remaining $5 \%$ of time spent co feeding, all instances were of individuals feeding on the same plant, but on a different part than their partner. Because all co feeding was executed on the same food plant, with less than $5 \%$ of observations showing discordance in the plant part being eaten, we grouped all co feeding into a single behaviour. There were no sex differences in the proportion of time

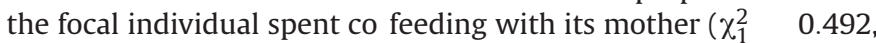
$P \quad 0.483$ ), and there were no significant differences among age categories in the total proportion of feeding time spent co feeding $\left(\chi_{5}^{2} \quad 6.177, P \quad 0.289\right.$; means: Infant $1 \quad 5.81 \%$; Infant $2 \quad 4.05 \%$; Juvenile 1 3.07\%; Juvenile 2 3.78\%; Subadult $8.61 \%$; Adult 6.84\%; Fig. 2). Infants and juveniles co fed more with their mothers than with other group members $\left(\chi_{7}^{2} \quad 57.704, P<0.001\right)$, and young infants showed slightly higher frequencies of co feeding with their mother than did older age categories, except for subadults (Fig. 2). Subadults maintained close associations with their mothers as they approached sexual maturity, and co fed slightly more with their mothers than did younger group members, but this difference was not significant.

While the proportion of time co feeding was low, behavioural synchrony with an individual's nearest neighbour during feeding and foraging was high (Fig. 3). Individuals in all age categories showed higher proportions of synchrony with their nearest neighbour during feeding and foraging than during other active (i.e. nonrest) behaviours $\left(\chi_{11}^{2} \quad 1507.3, P<0.001\right)$. Infants, in partic ular, showed the strongest difference between synchrony during feeding and synchrony during other activities, and were less likely to be in synchrony with their nearest neighbour during nonfeeding activities than were juveniles and older group members $\left(\chi_{5}^{2} \quad 316.69, P<0.001\right.$; Fig. 3$)$.

The relative age of a focal animal's nearest neighbour had the strongest effect on whether the two animals would be feeding at the same time (Fig. 3). During feeding and foraging, individuals were more likely to be in synchrony with their nearest neighbour when that neighbour was older $\left(\begin{array}{lll}\chi_{15}^{2} & 25.083, P & 0.048\end{array}\right)$, and they more likely to be feeding on the same food item $\left(\chi_{1}^{2} \quad 65.031\right.$, $P<0.001)$. There was no significant effect of sex on nearest neighbour distance during foraging and feeding $\left(\chi_{1}^{2} \quad 0.873\right.$, $P \quad$ 0.350). In contrast, during other activities (move, stand, groom, general social behaviours, play, and other), young individuals were more likely to be synchronized with their nearest neighbour when that neighbour was younger $\left(\chi_{15}^{2} \quad 329.47, P<0.001\right)$. There was no significant effect of sex on this synchrony $\left(\chi_{1}^{2} 3.02\right.$, $P \quad 0.082)$.

Juveniles and subadults had the most diverse diets within a social group across all seasons $\left(\chi_{5}^{2} \quad 52.342, P<0.001\right.$; Fig. 4$)$, which reflects more exploratory and trial and error foraging

Table 2

Mean \pm SE percentage of feeding observations on solid foods within each distance category

\begin{tabular}{|c|c|c|c|c|c|c|}
\hline Age & Sex & Touch & Reach & $1 \mathrm{~m}$ & $13 \mathrm{~m}$ & $>3 \mathrm{~m}$ \\
\hline \multirow[t]{2}{*}{ Infant 1} & $F$ & $31.46 \pm 0.00$ & $19.77 \pm 5.28$ & $33.86 \pm 0.00$ & $12.29 \pm 9.05$ & $2.68 \pm 0.03$ \\
\hline & M & $13.76 \pm 0.47$ & $23.22 \pm 6.70$ & $42.38 \pm 0.07$ & $17.56 \pm 12.23$ & $3.06 \pm 0.27$ \\
\hline \multirow[t]{2}{*}{ Infant 2} & $\mathrm{~F}$ & $4.34 \pm 0.59$ & $10.47 \pm 3.96$ & $38.28 \pm 0.10$ & $35.01 \pm 14.47$ & $11.84 \pm 0.78$ \\
\hline & M & $3.01 \pm 0.40$ & $8.36 \pm 2.96$ & $39.25 \pm 0.08$ & $38.38 \pm 13.88$ & $10.95 \pm 0.74$ \\
\hline \multirow[t]{2}{*}{ Juvenile 1} & $\mathrm{~F}$ & $1.64 \pm 0.46$ & $6.02 \pm 3.01$ & $28.85 \pm 0.05$ & $41.58 \pm 14.42$ & $21.85 \pm 0.53$ \\
\hline & M & $1.98 \pm 0.41$ & $3.65 \pm 1.82$ & $23.99 \pm 0.03$ & $44.31 \pm 12.00$ & $25.99 \pm 0.59$ \\
\hline \multirow[t]{2}{*}{ Juvenile 2} & $\mathrm{~F}$ & $2.18 \pm 0.52$ & $4.74 \pm 2.12$ & $22.89 \pm 0.06$ & $44.67 \pm 10.24$ & $25.47 \pm 0.52$ \\
\hline & M & $0.39 \pm 0.41$ & $3.5 \pm 1.42$ & $20.12 \pm 0.03$ & $43.62 \pm 8.21$ & $32.35 \pm 0.32$ \\
\hline \multirow[t]{2}{*}{ Subadult } & $\mathrm{F}$ & $0.83 \pm 0.09$ & $3.1 \pm 1.79$ & $21.64 \pm 0.05$ & $38.83 \pm 12.50$ & $35.58 \pm 0.66$ \\
\hline & M & $0.74 \pm 0.14$ & $2.47 \pm 0.93$ & $18.02 \pm 0.03$ & $43.52 \pm 6.81$ & $35.22 \pm 0.36$ \\
\hline \multirow[t]{2}{*}{ Adult } & $\mathrm{F}$ & $2.23 \pm 0.22$ & $3.69 \pm 0.81^{*}$ & $22.68 \pm 0.02^{*}$ & $41.93 \pm 4.95$ & $29.42 \pm 0.25^{*}$ \\
\hline & M & $0.72 \pm 0.08$ & $1.63 \pm 0.41^{*}$ & $12.74 \pm 0.01^{*}$ & $39.22 \pm 3.18$ & $45.67 \pm 0.19 *$ \\
\hline
\end{tabular}

Means are from GLMMs of the effects of age sex class on mean proportions of observations within each distance category to the nearest neighbour. Bold values indicate significant differences from adults; asterisks indicate sex differences within an age category. 


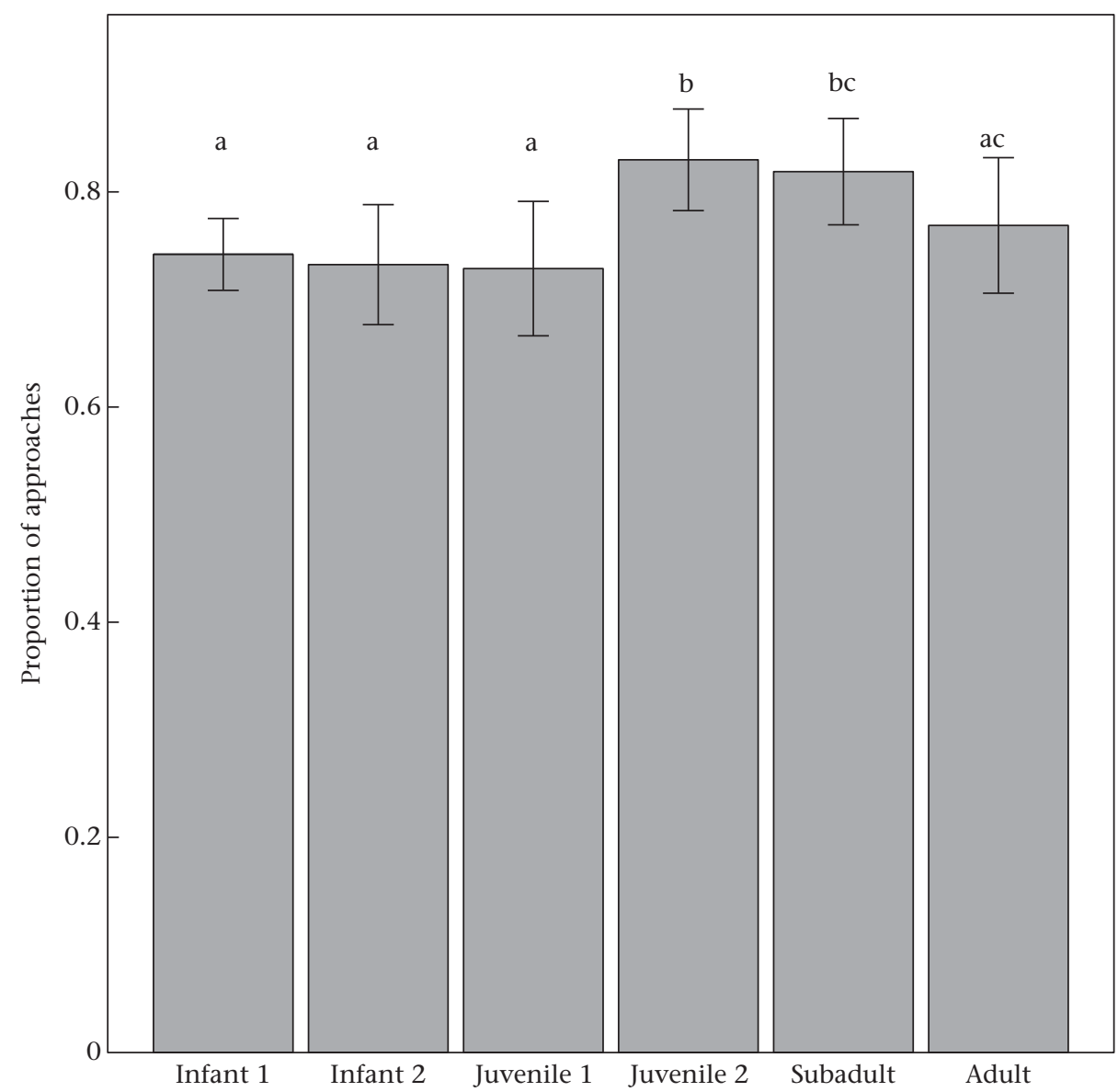

Figure 1. Mean \pm SE proportion of approaches directed towards a feeding or foraging conspecific. Letters above the bars join age classes with the same mean; age classes with different letters differed significantly from each other.

behaviour. Overall pairwise dietary overlap within a group was the same among all age classes, both between offspring and their mothers $\left(\chi_{4}^{2} \quad 5.561, P 0.234\right)$ and between other group members $\left(\chi_{5}^{2} \quad 8.521, P\right.$ 0.130). Therefore, regardless of the availability of food, juveniles and subadults sampled a wider array of plant species and plant parts, but still ate a largely overlapping diet with most group members.

\section{Diversity of Social Learning Behaviours in Ringtailed Lemurs}

Most of the social learning behaviours or tactics observed in other primates (Rapaport \& Brown 2008) were not found in ring tailed lemurs at any age. Voluntary food transfer or food offering was never observed, and ringtailed lemurs showed no stereotyped begging vocalization or gestures. Infants occasionally sniffed their mother's mouth while she was feeding on an item, but this did not occur regularly and was limited to novel foods such as insects, while feeding on soil, or on trash items taken by group members that ranged into the research camp. Scrounging or feeding imme diately on a discarded food item was also rare. Instead, animals scavenged on fruits that had been long discarded by other group members or even by members of other social groups. This typically occurred with the ripe fruit of Tamarindus indica. The hard shell of this fruit makes accessing the sticky pulp on the inside a consider able challenge, and ringtailed lemurs forage for discarded fruit pods on the ground, feeding on any remaining fruit in previously opened pods (Sauther 1992). Young juveniles were observed to steal food from others on two occasions. In the first case, a juvenile male stole a spider web from a subadult female, then ran away and quickly consumed the spider web. In a different social group, a young juvenile female of the group's dominant female showed a rare, but consistent behaviour where she would approach an individual that was subordinate to her mother (target) and attempt to co feed or share the target's food. If the target resisted, the juvenile would give a series of loud submissive calls directed at the target's mouth that drew her mother's attention. Her mother would then aggress at the target and the juvenile would come away with her desired food item. This juvenile female was the only individual observed to use this type of manipulation, and she used this technique several times in her infancy (S. L. Meredith, personal communication), as well during young juvenility. While an uncommon behaviour, this type of manipulative theft may be used to supplement the dietary knowledge of an infant or a juvenile.

\section{DISCUSSION}

Learning from older group members shapes vocalizations and mating calls (Cheney \& Seyfarth 1985; West et al. 2003), social and mate preferences (Godin et al. 2005), and diet (Heinsohn 1991; Galef \& Giraldeau 2001; Slagsvold \& Wiebe 2011). While the results of our study do not unequivocally demonstrate social learning in ringtailed lemurs, young ringtailed lemurs at the Beza Mahafaly Special Reserve showed behaviours consistent with social learning through generalized response facilitation or stimulus enhance ment. This basic social learning was executed through behavioural synchrony in feeding with a nearest neighbour, particularly when 


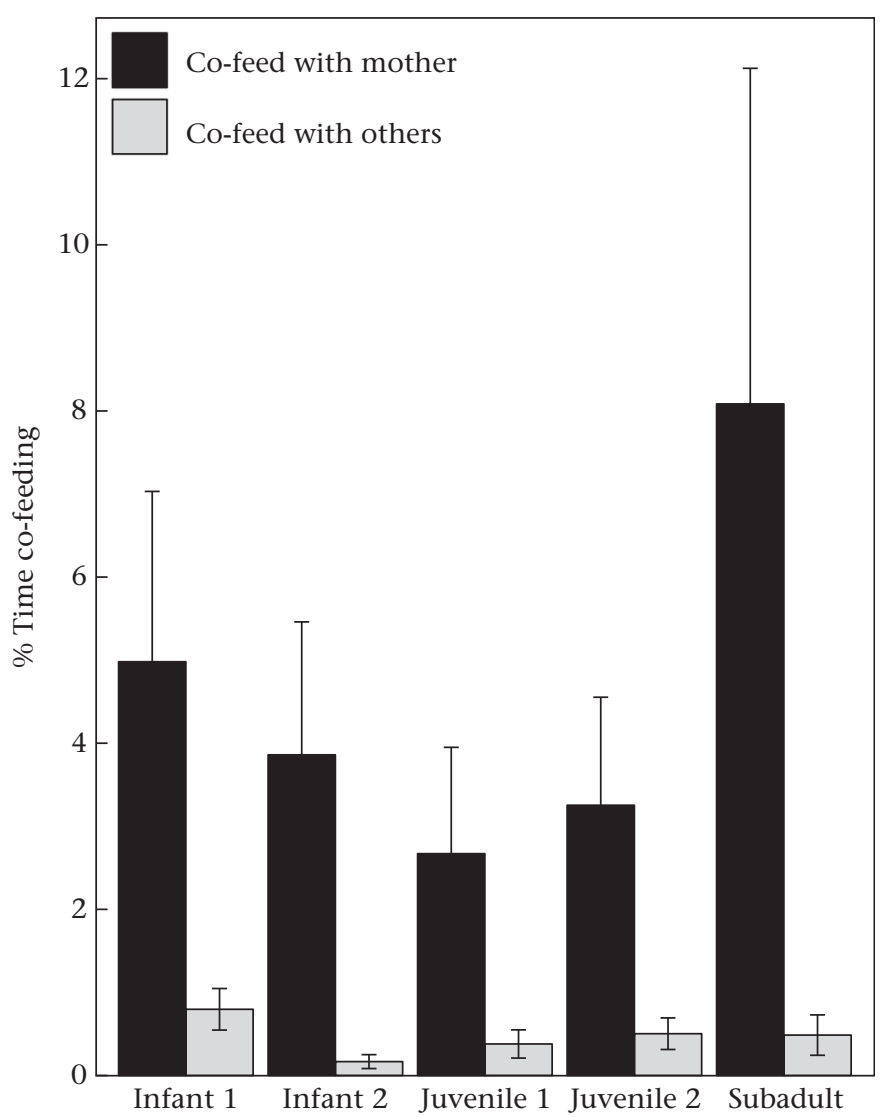

Figure 2. Mean $\pm S E$ percentage of time that focal individuals spent co-feeding on solid foods with their mother (black) and with other subadult and adult group members (grey).

that nearest neighbour was older. Social learning was supple mented by extensive exploration and trial and error learning by juveniles and subadults that showed high dietary diversity compared with other group members. The development of feeding ecology in ringtailed lemurs thus appears to be guided by social learning through synchrony with a nearest neighbour and personal environmental exploration.

Ringtailed lemurs have the largest social groups of the strep sirrhine primates, and they feed on an eclectic generalist diet and show relatively high social cognition (Sandel et al. 2011). Social learning, then, should be an integral part of their dietary and ecological development (Thornton \& Clutton Brock 2011). Ring tailed lemurs do not use most of the social learning behaviours previously described for other primates during execution of their daily feeding behaviour (Rapaport \& Brown 2008), but instead use simple social learning strategies and rules common to wild verte brates and consistent with stimulus enhancement and response facilitation (Sherwin et al. 2002; Laland 2004; Hoppitt \& Laland 2008; Mersmann et al. 2011). This bias towards feeding synchrony with larger, older and, probably, more well informed individuals is a common strategy (i.e. prestige bias; Richerson \& Boyd 2005) in a variety of species, including nine spined stickle backs, Pungitius pungitius (Duffy et al. 2009) and mice (Choleris et al. 1997), as well as other primates (Altmann 1980; Nicholson 1982; King 1991, 1994; Matsuzawa et al. 2001; Biro et al. 2003; Tarnaud 2004). Despite significant adult sex differences in diet (M. T. O'Mara \& C. M. Hickey, unpublished data), the lack of a significant effect of nearest neighbour sex on the likelihood of feeding synchrony indicates no bias towards same sex individuals, and suggests that feeding synchrony with nearest neighbours is not the primary mechanism by which adult sex differences develop. Social learning of diet through these generalized learning strategies is probably powerful enough to shape an individual's entire feeding ecology, making more complex learning behaviours unnecessary for a diet that does not include risky or complex extractive foraging (Mersmann et al. 2011). For example, cross fostering experiments with great tits, Parus major, and blue tits, Cyanistes caeruleus, indicate that offspring learn diets early, and that early learning experiences with cross fostered host species persist throughout adulthood (Slagsvold \& Wiebe 2007, 2011). These experiments indicate that diet and the ecological niche of these tit species are most likely learned through the same social learning rules (feed when an older group member feeds) and show the effects of local enhancement and the coordination for foraging with older group members. The selective and discriminatory use of information by growing individuals is then common across social vertebrates, and probably represents one of the most fundamental rules of social learning. However, further work is needed to understand how generalizable the information learned in these context really are, how often this information has to be reinforced and how long it is retained.

Co feeding as been identified as a valuable behaviour where young can learn from older individuals. As a social learning behaviour, co feeding is motivated by the learner, and has a specific target, whether it is an individual's mother (Hauser 1993; Ueno 2005), or a group member of the same sex. Co feeding allows for close and direct contact with the food that a partner is eating and provides information about what that food is, where it can be found, and how it needs to be processed. High levels of co feeding by offspring and their mothers are often reported in primate studies (e.g. vervet monkeys: 35-55\%; Hauser 1993; macaques, Macaca fuscata: 60-100\%; Ueno 2005; aye ayes, Daubentonia madagascariensis: 20-40\%; Krakauer 2005), but co feeding has received less focus in other taxa. Co feeding probably occurs in other taxa, but is most likely included in other levels of social facilitation or maternal influences on behaviour (Galef \& Giraldeau 2001). Co feeding is uncommon in ringtailed lemurs, but was observed at low levels throughout nutritional dependency (Fig. 2). Similarly, infants of the frugivorous ruffed lemur, Varecia rubra, do not co feed with their mothers in captivity (Krakauer 2005). When taken together, these two lemur species reflect a broad pattern of basic social learning, with exploration and trial and error learning having a stronger influence on the development of feeding in species that are dietary generalists. In captivity, juvenile ringtailed lemurs are the first in their social groups to explore and learn new foraging techniques (Feldman \& Klopfer 1972; Kappeler 1987). The high dietary diversity of juveniles, when controlling for season and food availability (Fig. 4), reflects this motivation to explore their environment.

Infant and juvenile ringtailed lemurs did not use most of the stereotypical learning behaviours previously described for other primates (Rapaport \& Brown 2008). Social learning by adult ring tailed lemurs has been inferred through dual action puzzle exper iments in both captive and wild settings (Kendal et al. 2010), and it is interesting that the adult capacity for social learning displayed in experimental manipulations does not reflect common behavioural patterns in immature individuals in a wild population. The rigid dominance hierarchy in ringtailed lemurs may limit learning opportunities to members of the same social clique (Kendal et al. 2010), and this agonistic exclusion may make more focused social learning, such as co feeding, an infrequent strategy for adoption of new foods into the diet. Infants and juveniles instead appear to use response facilitation or stimulus enhancement type tactics focused on older group members (Fig. 3). The act of an older neighbour feeding may provide much of the social information necessary to 


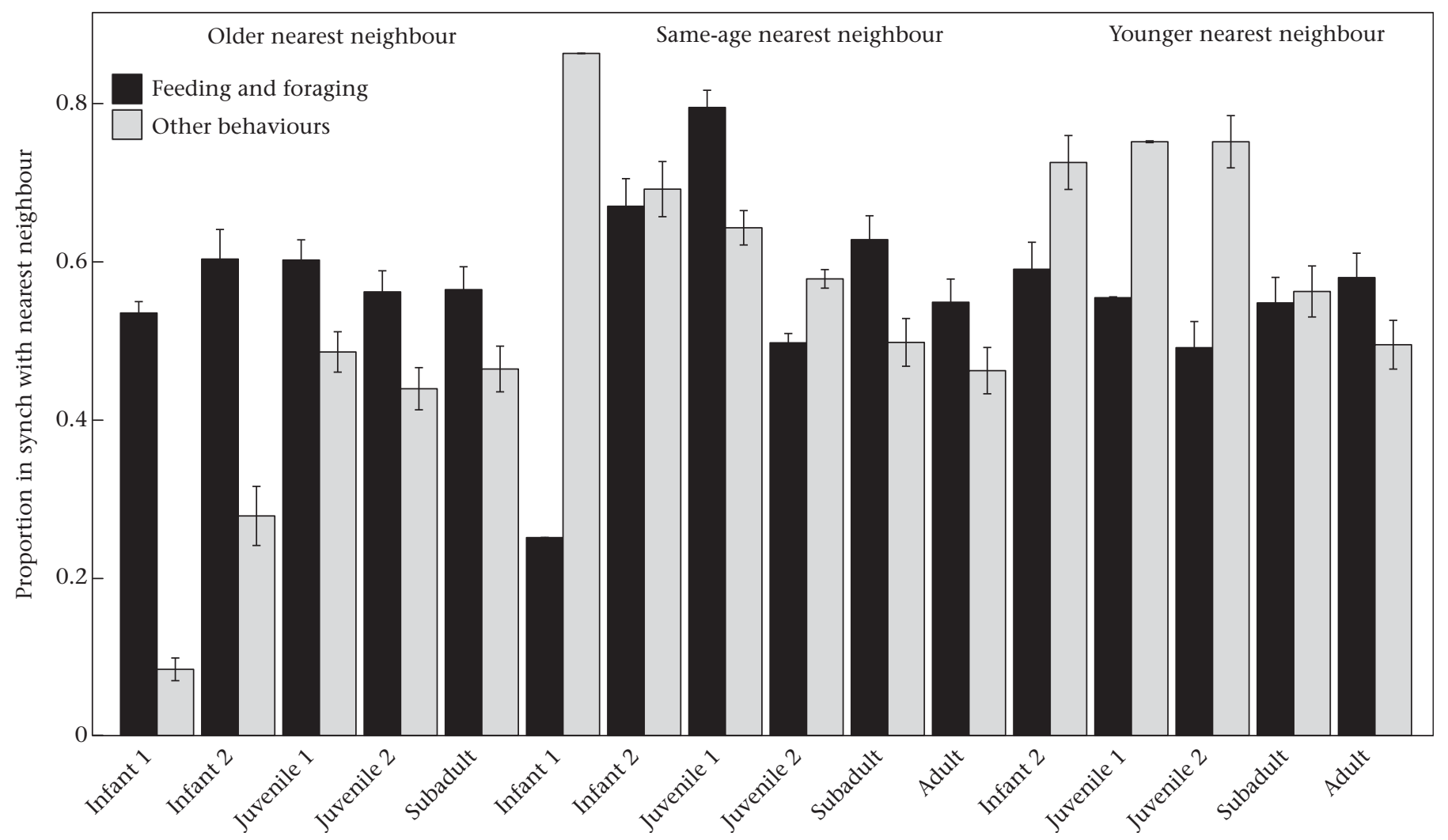

Figure 3. Mean \pm SE proportion of bouts of feeding and foraging (black) and other active behaviours (grey) during which an individual was in synchrony with its nearest neighbour.

learn feeding ecology and may function as a stimulus that induces young animals to feed.

Overall, ringtailed lemurs develop adult like dietary composi tion and competency early in juvenility (O'Mara 2012). The rapid change in seasonality and the unpredictable nature of rainfall in southern Madagascar (Dewar \& Richard 2007; Lawler et al. 2009) may favour individuals that can learn from as many social partners as quickly as possible, while including extensive individual trial and error learning so that juveniles can survive their first dry season of low food availability. Both their intolerant dominance

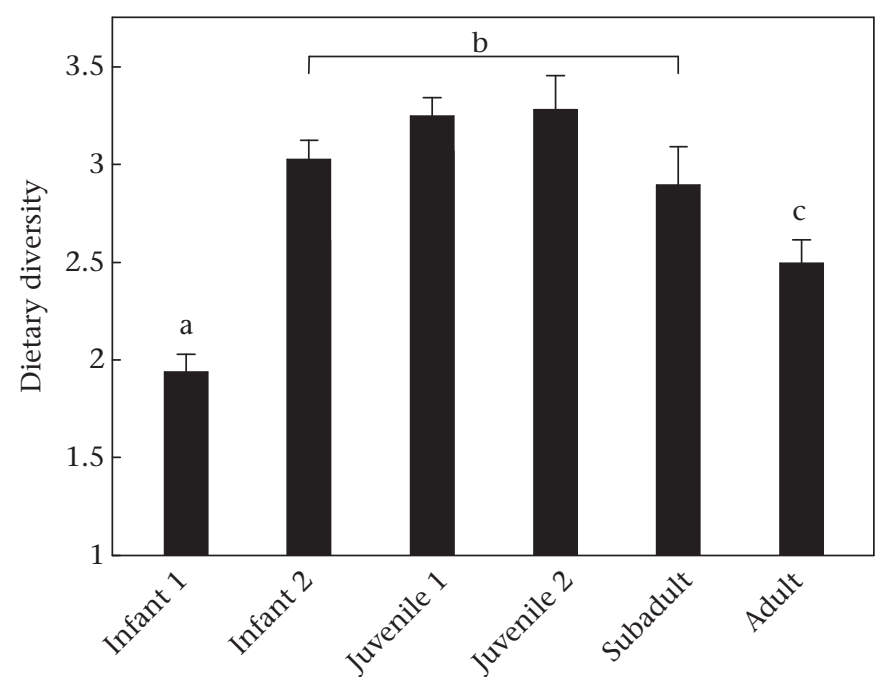

Figure 4. Mean \pm SE Simpson's inverse diversity index. Different letters above bars denote significant differences $(P<0.05)$ in dietary diversity scores between age classes. hierarchy and an unpredictable resource environment may limit the diversity of social learning behaviours used by ringtailed lemurs and reinforce more general learning strategies. The seasonal and year to year variability in resource abundance is such that a growing individual may not be exposed to resource types within the span of 1 or even 2 years (Dewar \& Richard 2007; Lawler et al. 2009), the ages when mothers are tolerant of their offspring feeding closely with them. After this point, the use of social learning behaviours that involve close proximity would not be useful, as offspring would be agonistically excluded from feeding sites. The use of social learning strategies that rely on stimulus enhancement may be flexible and called into action throughout development and adulthood when resources and social stability permit. Simply feeding when another individual feeds may be the best strategy to learn about new resources when living in both an intolerant social hierarchy and an unpredictable environment.

Our results show that wild ringtailed lemur infants and juve niles execute foraging behaviours that are consistent with basic social learning strategies by synchronizing their behaviour with a nearest neighbour. Young ringtailed lemurs do not use social learning behaviours such as co feeding as frequently as do monkeys, but they do engage in basic social learning during much of their feeding and foraging time. The basic learning rules of feeding when a close, older individual feeds and of individual exploration may provide the foundation for the more elaborate social learning needed for complex extractive foraging and tool manufacture, and the evolution of transgenerational transmission of traditions.

\section{Acknowledgments}

We thank Ayden Sherritt, Paul Stephen and Andy Fogel for their enormous help with data collection. We thank Madagascar 
National Parks, the Ministére des Eaux et Forêt and ESSA Forêt Université d'Antananarivo for permission to conduct this study and the staff at Beza Mahafaly and the Madagascar Insitut pour la Conservation des Environnements Tropicaux (MICET) for facili tating the logistics of this work. Michelle Sauther, Frank Cuozzo, Jacky Antho, Stephanie Meredith, Andry Randrianandrasana, Jean nin Ranaivonasy, Benjamin Andriamihaja, Monja, and the members of the Beza Mahafaly Ecological Monitoring Team were all highly supportive of the fieldwork at Beza. Special thanks also to Alison Richard and Robert Dewar for their support of this project. Leanne Nash, Kate Ihle and Patricia Jones provided insightful comments on previous drafts of this manuscript, as did two anonymous referees. Justin Touchon and Stuart Dennis provided statistical advice. This work was funded with support to M.T.O. from the National Science Foundation (DDIG BCS 0851761), the J. William Fulbright Founda tion, Primate Conservation, Inc., Sigma Xi and its Arizona State University (ASU) chapter, the ASU Graduate and Professional Students Association, and the ASU School of Human Evolution \& Social Change.

\section{References}

Altmann, J. 1974. Observational study of behavior: sampling methods. Behaviour 49, 227265

Altmann, J. 1980. Baboon Mothers and Infants. Cambridge, Massachusetts: Harvard University Press.

Altmann, S. A. 1991. Diet of yearling female primates (Papio cynocephalus) predicts lifetime fitness. Proceedings of the National Academy of Sciences, U.S.A., 88 420423.

Anderson, J. R., Fornasieri, I., Ludes, E. \& Roeder, J. J. 1992. Social processes and innovative behavior in changing groups of Lemur fulvus. Behavioural Processes, 27, 101112

Begon, M., Harper, J. \& Townsend, C. 1996. Ecology. Oxford: Blackwell Science.

Biro, D. Inoue-Nakamura, N , Tonooka, $R$, Yamakoshi, G Sousa, C. \& Matsuzawa, T. 2003. Cultural innovation and transmission of tool use in wild chimpanzees: evidence from field experiments. Animal Cognition, 6, 213223.

Carter, A. J., Marshall, H. H., Heinsohn, R. \& Cowlishaw, G. 2012. How not to measure boldness: novel object and antipredator responses are not the same in wild baboons. Animal Behaviour, 84, 603609.

Cheney, D. L. \& Seyfarth, R. M. 1985. Vervet monkey alarm calls: manipulation through shared information. Behaviour, 94, 150166

Choleris, E., Guo, C., Liu, H., Mainardi, M. \& Valsecchi, P. 1997. The effect of demonstrator age and number on duration of socially-induced food preferences in house mouse (Mus domesticus). Behavioural Processes, 41, 6977.

Coelho, A. M. \& Bramblett, C. A. 1981. Interobserver agreement on a molecular ethogram of the genus Papio. Animal Behaviour, 29, 443448

Dagosto, M. 1994. Testing positional behavior of Malagasy lemurs: a randomization approach. American Journal of Physical Anthropology, 94, 189202

Dean, L. G., Hoppitt, W., Laland, K. N. \& Kendal, R. L. 2011. Sex ratio affects sexspecific innovation and learning in captive ruffed lemurs (Varecia variegata and Varecia rubra). American Journal of Primatology, 73, 12101221.

Dewar, R. \& Richard, A. 2007. Evolution in the hypervariable environment of Madagascar. Proceedings of the National Academy of Sciences, U.S.A., 104, 1372313727.

Dindo, M., Whiten, A. \& de Waal, F. 2009. Social facilitation of exploratory foraging behavior in capuchin monkeys (Cebus apella). American Journal of Primatology, 71, 419426.

Duffy, G. A., Pike, T. W. \& Laland, K. N. 2009. Size-dependent directed social learning in nine-spined sticklebacks. Animal Behaviour, 78, 371375.

Emery, N. J. \& Clayton, N. S. 2004. The mentality of crows: convergent evolution of intelligence in corvids and apes. Science, 306, 19031907.

Feldman, D. W. \& Klopfer, P. H. 1972. A study of observational learning in lemurs. Zeitschrift für Tierpsychologie, 30, 297304.

Galef, B. G. \& Giraldeau, L.-A. 2001. Social influences on foraging in vertebrates: causal mechanisms and adaptive functions. Animal Behaviour, 61, 315.

Godin, J. G. J., Herdman, E. J. E. \& Dugatkin, L. A. 2005. Social influences on female mate choice in the guppy, Poecilia reticulata: generalized and repeatable traitcopying behaviour. Animal Behaviour, 69, 9991005.

Gosset, D. \& Roeder, J. J. 2001. Factors affecting feeding decisions in a group of black lemurs confronted with novel food. Primates, 42, 175182

Gould, L. 1990. The social development of free-ranging infant Lemur catta at Berenty Reserve, Madagascar. International Journal of Primatology, 11, 297318

Hauser, M. D. 1993. Ontogeny of foraging behavior in wild vervet monkeys (Cercopithecus aethiops): social interactions and survival. Journal of Comparative Psychology, 107, 276282.

Heinsohn, R. G. 1991. Slow learning of foraging skills and extended parental care in cooperatively breeding white-winged choughs. American Naturalist, 137, 864881
Heyes, C. 1994. Social learning in animals: categories and mechanisms. Biological Reviews of the Cambridge Philosophical Society, 69, 207231.

Hilborn, A., Pettorelli, N., Orme, C. D. L. \& Durant, S. M. 2012. Stalk and chase: how hunt stages affect hunting success in Serengeti cheetah. Animal Behaviour 84, 701706.

Hoppitt, W. \& Laland, K. 2008. Social processes influencing learning in animals: review of the evidence. Advances in the Study of Behavior, 38, 105165.

Hosey, G. R., Jacques, M. \& Pitts, A. 1997. Drinking from tails: social learning of a novel behaviour in a group of ring-tailed lemurs (Lemur catta). Primates, 38 415422.

Huchard, E., Canale, C., Le, G. C., Perret, M., Henry, P. \& Kappeler, P. 2012. Convenience polyandry or convenience polygyny? Costly sex under female control in a promiscuous primate. Proceedings of the Royal Society $B, \mathbf{2 7 9}$, 13711379.

Humle, T. \& Snowdon, C. T. 2008. Socially biased learning in the acquisition of complex foraging task in juvenile cottontop tamarins, Saguinus oedipus. Animal Behaviour, 75, 267277.

Irwin, M. 2008. Feeding ecology of Propithecus diadema in forest fragments and continuous forest. International Journal of Primatology, 29, 95115.

Jaeger, T. 2008. Categorical data analysis: away from ANOVAs (transformation or not) and towards logit mixed models. Journal of Memory and Language, 59, 434446.

Joffe, T. H. 1997. Social pressures have selected for an extended juvenile period in primates. Journal of Human Evolution, 32, 593605.

Jolly, A. 1966a. Lemur Behavior, a Madagascar Field Study. Chicago: University of Chicago Press.

Jolly, A. 1966b. Lemur social behavior and primate intelligence. Science, 153 501506

Kappeler, P. M. 1987. The acquisition process of a novel behavior pattern in a group of ring-tailed lemurs (Lemur catta). Primates, 28, 225228.

Kawai, M. 1965. Newly-acquired pre-cultural behavior of the natural troop of Japanese monkeys on Koshima Islet. Primates, 6, 130.

Kendal, J., Giraldeau, L.-A. \& Laland, K. 2009. The evolution of social learning rules: payoff-biased and frequency-dependent biased transmission. Journal of Theoretical Biology, 260, 210219.

Kendal, R. L., Custance, D. M., Kendal, J. R., Vale, G., Stoinski, T. S. Rakotomalala, N. L. \& Rasamimanana, H. 2010. Evidence for social learning in wild lemurs (Lemur catta). Learning \& Behavior, 38, 220234.

King, B. J. 1991. Social information transfer in monkeys, apes, and hominids. Yearbook of Physical Anthropology, 34, 97115.

King, B. J. 1994. Primate infants as skilled information gatherers. Pre- and Perinatal Psychology Journal, 8, 287307.

Krakauer, E. B. 2005. Development of aye-aye (Daubentonia madagascariensis) foraging skills: independent exploration and social learning. Ph.D. thesis, Duke University.

Laland, K. N. 2004. Social learning strategies. Learning E Behavior, 32, 414

Laland, K. \& Janik, V. 2006. The animal cultures debate. Trends in Ecology $\mathcal{E}$ Evolution, 21, 542547.

Lawler, R., Caswell, H., Richard, A., Ratsirarson, J., Dewar, R. \& Schwartz, M. 2009 Demography of Verreaux's sifaka in a stochastic rainfall environment. Oecologia, 161, 491504.

Lewis, F., Butler, A. \& Gilbert, L. 2011. A unified approach to model selection using the likelihood ratio test. Methods in Ecology and Evolution, 2, 155162.

Luncz, L., Mundry, R. \& Boesch, C. 2012. Evidence for cultural differences between neighboring chimpanzee communities. Current Biology, 22, 922926.

Machlis, L., Dodd, P. \& Fentress, J. 1985. The pooling fallacy: problems arising when individuals contribute more than one observation to the data set. Zeitschrift für Tierpsychologie, 68, 201214.

Matsuzawa, T., Biro, D., Humle, T., Inoue-Nakamura, N., Tonooka, R. \& Yamakoshi, G. 2001. Emergence of culture in wild chimpanzees: education by master apprenticeship. In: Primate Origins of Human Cognition and Behavior (Ed. by T. Matsuzawa), pp. 557 574. Berlin: Springer.

Mersmann, D., Tomasello, M., Call, J., Kaminski, J. \& Taborsky, M. 2011. Simple mechanisms can explain social learning in domestic dogs (Canis familiaris). Ethology, 117, 675690

Mery, F. \& Kawecki, T. J. 2004. An operating cost of learning in Drosophila melanogaster. Animal Behaviour, 68, 589598.

Nicholson, N. 1982. Weaning and the development of independence in olive baboons. Ph.D. thesis, Harvard University.

O'Mara, M. T. 2012. Development of feeding in ring-tailed lemurs. Ph.D. thesis, Arizona State University.

Page, R. \& Ryan, M. 2005. Flexibility in assessment of prey cues: frog-eating bats and frog calls. Proceedings of the Royal Society B, 272, 841847.

Pereira, M. E. \& Kappeler, P. M. 1997. Divergent systems of agonistic behaviour in lemurid primates. Behaviour, 134, 225274

Perry, S. 2011. Social traditions and social learning in capuchin monkeys (Cebus). Philosophical Transactions of the Royal Society B, 366, 988996.

Pianka, E. R. 1973. The structure of lizard communities. Annual Review of Ecology and Systematics, 4, 5374

Pinheiro, J. C. \& Bates, D. M. 2009. Mixed-effects Models in S and S-plus. Berlin: Springer.

R Development Core Team 2011. R: a Language and Environment for Statistical Computing. Vienna: R Foundation for Statistical Computing

Rapaport, L. \& Brown, G. 2008. Social influences on foraging behavior in young nonhuman primates: learning what, where, and how to eat. Evolutionary Anthropology, 17, 189201. 
Rendell, L., Boyd, R., Cownden, D., Enquist, M., Eriksson, K., Feldman, M., Fogarty, L., Ghirlanda, S., Lillicrap, T. \& Laland, K. 2010. Why copy others? Insights from the social learning strategies tournament. Science, 328, 208.

Richerson, P. \& Boyd, R. 2005. Not by Genes Alone: How Culture Transformed Human Evolution. Chicago: University of Chicago Press.

Ross, C. \& Jones, K. 1999. Socioecology and the evolution of primate reproductive rates. In: Comparative Primate Socioecology (Ed. by P. C. Lee), pp. 73110. Cambridge: Cambridge University Press.

Sandel, A. A., Maclean, E. L. \& Hare, B. 2011. Evidence from four lemur species that ringtailed lemur social cognition converges with that of haplorhine primates. Animal Behaviour, 81, 925931.

Sauther, M. L. 1991. Reproductive behavior of free-ranging Lemur catta at Beza Mahafaly Special Reserve, Madagascar. American Journal of Physical Anthropology, 84, 463477.

Sauther, M. L. 1992. The effect of reproductive state, social rank and group size on resource use among free-ranging ringtailed lemurs (Lemur catta) of Madagascar. Ph.D. thesis, Washington University.

van Schaik, C. P. 2012. Animal culture: chimpanzee conformity? Current Biology, 22, R402 R404.

van Schaik, C. P. \& Burkart, J. 2011. Social learning and evolution: the cultural intelligence hypothesis. Philosophical Transactions of the Royal Society B, 366, 10081016.

Sherwin, C. M. Heyes, C. M. \& Nicol, C. J. 2002. Social learning influences the preferences of domestic hens for novel food. Animal Behaviour, 63, 933942.

Slagsvold, T. \& Wiebe, K. 2007. Learning the ecological niche. Proceedings of the Royal Society B, 274, 1923

Slagsvold, T. \& Wiebe, K. L. 2011. Social learning in birds and its role in shaping a foraging niche. Philosophical Transactions of the Royal Society B, 366, 969977.

Stoinski, T., Drayton, L. \& Price, E. 2011. Evidence of social learning in black-andwhite ruffed lemurs (Varecia variegata). Biology Letters, 7, 376379.

Sussman, R. W. \& Ratsirarson, J. 2006. Beza Mahafaly Special Reserve: a research site in southwestern Madagascar. In: Ringtailed Lemur Biology: Lemur catta in Madagascar (Ed. by A. Jolly, R. W. Sussman, N. Koyama \& H. Rasamimanana), pp. 43 51. Berlin: Springer.
Tarnaud, L. 2004. Ontogeny of feeding behavior of Eulemur fulvus in the dry forest of Mayotte. International Journal of Primatology, 25, 803824.

Thornton, A. \& Clutton-Brock, T. 2011. Social learning and the development of individual and group behaviour in mammal societies. Philosophical Transactions of the Royal Society B, 366, 978987.

Thornton, A. \& McAuliffe, K. 2006. Teaching in wild meerkats. Science, 313, 227229.

Thornton, A. \& Raihani, N. J. 2008. The evolution of teaching. Animal Behaviour, 75, 18231836.

Toelch, U., Van Delft, M. J., Bruce, M., Donders, R., Meeus, M. \& Reader, S. 2009. Decreased environmental variability induces a bias for social information use in humans. Evolution and Human Behavior, 30, 3240.

Ueno, A. 2005. Development of co-feeding behavior in young wild Japanese macaques (Macaca fuscata). Infant Behavior \& Development, 28, 481491.

van de Waal, E. \& Bshary, R. 2011. Social-learning abilities of wild vervet monkeys in a two-step task artificial fruit experiment. Animal Behaviour, 81, 433438.

van de Waal, E., Renevey, N., Favre, C. \& Bshary, R. 2010. Selective attention to philopatric models causes directed social learning in wild vervet monkeys. Proceedings of the Royal Society B, 277, 21052111.

van de Waal, E., Krützen, M., Hula, J., Goudet, J. \& Bshary, R. 2012. Similarity in food cleaning techniques within matrilines in wild vervet monkeys. PLoS One, 7, e35694.

Warton, D. \& Hui, F. 2011. The arcsine is asinine: the analysis of proportions in ecology. Ecology, 92, 310.

West, M. J., King, A. P. \& White, D. J. 2003. The case for developmental ecology. Animal Behaviour, 66, 617622.

Whiten, A. 2000. Primate culture and social learning. Cognitive Science, 24, 477508.

Whiten, A. 2011. The scope of culture in chimpanzees, humans and ancestral apes. Philosophical Transactions of the Royal Society B, 366, 9971007.

Whiten, A. Goodall, J., Mcgrew, W., Nishida, T., Reynolds, V., Sugiyama, Y., Tutin, C., Wrangham, R. \& Boesch, C. 1999. Cultures in chimpanzees. Nature, 399, 682685. 